J. chron. Dis. 1970, Vol. 22, pp. 579-592. Pergamon Press. Printed in Great Britain

\title{
THE DROPOUT PROBLEM IN ANTIHYPERTENSIVE TREATMENT
}

\author{
A PILOT STUDY OF SOCIAL AND EMOTIONAL FACTORS \\ INFLUENCING A PATIENT'S ABILITY TO FOLLOW \\ ANTIHYPERTENSIVE TREATMENT*
}

\author{
John R. Caldwell, M.D.†, Sidney Cobb, M.D., M.P.H.ł, \\ Monroe D. Dowling, M.D. \and Dasua DE Jongh, M.S.W. $\uparrow$
}

(Received 10 March 1969; in revised form 22 July 1969)

\section{INTRODUCTION}

IN THE past decade there has been a 44 per cent reduction in death rates due to hypertensive heart disease [1]. This improvement in mortality is probably attributable to the notable progress in antihypertensive drug treatment during the same period of time.

We have learned, however, that hypertension, like diabetes, requires life long medical supervision. A substantial proportion of patients drop out of treatment. Some of these patients who abandon antihypertensive treatment turn up in the hospital emergency room with a serious complication of uncontrolled hypertensive disease which in some cases is disastrous.

We have found that many patients coming to the Emergency Room of the Henry Ford Hospital with a hypertensive crisis have stopped previous antihypertensive treatment. This finding raised 2 questions: (1) How many patients drop out of treatment for hypertensive disease? (2) Why do patients drop out of treatment?

In order to answer the first question, we studied losses from the hypertension division among 76 patients first seen in the year 1961 and for whom treatment was undertaken by the clinic. All of these patients were new to Henry Ford Hospital in 1961, and were found to have an established diastolic hypertension as evidenced by a basal diastolic blood pressure of $90 \mathrm{~mm} \mathrm{Hg}$ or above. A patient was regarded as lost from the clinic if there was no evidence of referral to another physician, and if the patient had been inconsistent in that he had not returned on or within 3 months after the date of the scheduled return visit, or had discontinued medication for 30 days or more. By 11 months 50 per cent of those patients studied had been

\footnotetext{
*This study was supported by a grant from the Michigan Heart Association. †Department of Medicine, Henry Ford Hospital, Detroit, Michigan. $\ddagger$ Institute for Social Research, University of Michigan, Ann Arbor, Michigan. §Sloan Kettering Institute for Cancer Research, New York, New York. †Department of Social Work, Henry Ford Hospital, Detroit, Michigan.
} 


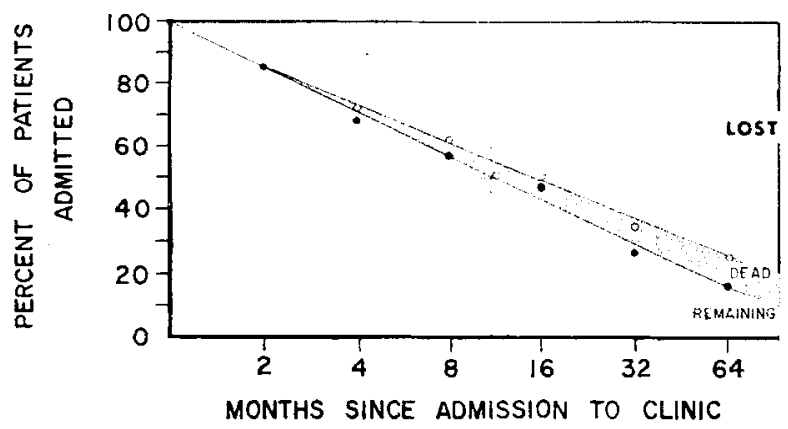

Fig. 1. A semi-logarithmic plot of the losses from the hypertension clinic over a 64-month period.

lost from the clinic and by $5 \mathrm{yr}, 74$ per cent had dropped out, 9 per cent had died and only 17 per cent were remaining in treatment (Fig. 1).

These percentages show the tremendous number who drop out of treatment among patients who are in need of antihypertensive treatment. With respect to the need for treatment, we are in agreement with Smirk [2] who asserts that treatment in hypertension is only clearly indicated when the basal blood pressure is elevated.

It seems reasonable to assume that perhaps only a small percentage of the 74 per cent who were lost to treatment in this $5 \mathrm{yr}$ follow-up study had a serious enough form of hypertensive disease to develop an emergency during the $5 \mathrm{yr}$ period. We do not have data on these patients to document the severity of their disease, but this brief study does point up the magnitude of the dropout problem among patients attending a clinic for management of hypertension.

The answer to the second question raised, i.e., why do patients drop out of treatment is much more complex and it is to this question that the main body of our inquiry is addressed.

By finding out why patients drop out of treatment we may find ways to assist patients in following and remaining in treatment thus reducing the morbidity and mortality of hypertensive disease.

Since the drop out rate is so high and the consequences so serious in some patients who have been selected for long term antihypertensive treatment, let us now look at a selected group of patients who developed a true hypertensive emergency after discontinuing therapy.

\section{DESCRIPTION OF THE STUDY-METHODS}

\section{Selection of cases}

Forty-two (42) patients who had developed a hypertensive emergency after discontinuing treatment were studied as the Emergency Group. They had all been seen at the Henry Ford Hospital Emergency Room between April 1964 and December 1965 for treatment. This Emergency Group was compared with a Control Group of 24 patients who had remained in treatment for severe or malignant hypertensive disease in the Hypertension Division during the last 5 yr or longer. 
The Emergency Group had the following diagnoses on admission to the emergency ward; encephalopathy 21 per cent, congestive heart failure 17 per cent, epistaxis 14 per cent, intracranial hemorrhage 10 per cent, acute arterial occlusion 10 per cent, acute renal complication 2 per cent and other emergencies 26 per cent (Table 1).

Examples of 'other emergencies' included individual cases with diagnoses such as syncope, central retinal vein thrombosis, paroxysmal atrial tachycardia, severe headaches, anxiety and paresthesias, acute atrial fibrillation, etc., associated with markedly elevated blood pressure levels. Two patients died within 1 month of the emergency.

The time without treatment was less than $1 \mathrm{yr}$ in 24 per cent of the patients, from 1-2 yr in 17 per cent and more than 2 yr in 40 per cent. The time without treatment could not be determined in 19 per cent of the patients. Previous treatment had consisted of drugs in 91 per cent and dietary restriction in 45 per cent of the patients. Many of the patients were treated with both drugs and diet. In 9 per cent of the patients the nature of the previous treatment was unknown.

The blood pressure levels at the time of the hypertensive emergencies were usually over $200 \mathrm{~mm} \mathrm{Hg}$ systolic and over $130 \mathrm{~mm} \mathrm{Hg}$ diastolic. Systolic blood pressures were between 150-199 mm Hg in 10 per cent, between 200-249 in 64 per cent and were 250 or over in 26 per cent. The diastolic blood pressures were under $110 \mathrm{~mm} \mathrm{Hg}$ in 12 per cent, $110-129$ in 19 per cent, $130-149$ in 40 per cent and 150 or over in 29 per cent.

\section{COMPARABILITY OF CASES}

The emergency group and the control group were comparable with respect to sex, marital status, number of children in the families, religion and presence of other chronic diseases. No significant differences between the 2 groups was noted in these areas. The severity of disease at the time of first admission for hypertension was

TABLE 1. EMERGENCY Diagnoses (42 PATIENTS)

\begin{tabular}{lr}
\hline Encephalopathy & 21 per cent \\
Congestive heart failure & 17 per cent \\
Epistaxis & 14 per cent \\
Intracranial hemorrhage & 10 per cent \\
Acute arterial occlusion & 10 per cent \\
Acute renal complication & 2 per cent \\
Other & 26 per cent \\
\hline
\end{tabular}

TABLE 2. SEVERITY OF DISEASE

\begin{tabular}{lcc}
\hline \multicolumn{1}{c}{ Criteria } & $\begin{array}{c}\text { Emergency group } \\
\text { (42 patients) } \\
(\%)\end{array}$ & $\begin{array}{c}\text { Control Group } \\
(24 \text { patients) } \\
(\%)\end{array}$ \\
\hline Retinopathy grade III or IV & 45 & 42 \\
Left ventricular hypertrophy & 81 & 71 \\
Azotemia & 45 & 29 \\
Basal diastolic $100+$ & 88 & 88 \\
\hline
\end{tabular}


comparable for the two groups. Determination of severity was based on findings at funduscopic examination, electrocardiogram, serum creatinine and pretreatment basal or in-hospital diastolic blood pressure level. The retinal grading referred to is according to the classification of Keith, Wagener and Barker [3]. The criteria for left ventricular hypertrophy was that of Sokolow and Lyon [4]. Azotemia was defined as serum creatinine of $1.5 \mathrm{mg} / 100 \mathrm{ml}$ or above and basal blood pressures were measured by a modification of the Smirk method described by Caldwell and Hollinger [5] (Table 2).

\section{DESIGN OF STUDY}

In an effort to find out why the patients stopped drug treatment, patients in the emergency group were interviewed briefly by the physician just after investigation and management of the medical problem had been instituted. At a later date but usually still during their hospitalization, the patients were interviewed by the social worker. In those cases where the patient was unable to communicate, close relatives were interviewed.

The patients in the control group were interviewed by the social worker in a scheduled out-patient appointment. They had responded to an explanatory letter requesting their help which was sent by the physician.

In these interviews pertinent data was obtained concerning the patient's life history, his social situation, and his medical problem from his own point of view. The following areas were explored: age, sex, race, marital status, number of children, religion, birthplace, childhood environment, adult environment, education of patient and spouse, income and source, financial status with regard to home ownership, occupation and work status, medical situation of patient and family, and reasons for continuing or discontinuing treatment. From the medical history information was gathered regarding the emergency diagnosis, the blood pressure at the time of emergency, and the presence of other chronic diseases in the patient. From both history and interviews, data was obtained concerning the duration of known hypertension, the type of treatment previously received, and the family history of hypertension. All data was processed on McBee Keysort Cards after development of an appropriate coding system.

\section{DATA EXAMINED}

The data in the two groups of patients was compared as to age, race, education, occupation, income, duration of disease, and characteristic differences between the two groups. In processing the data, the two groups were compared as far as their medical situations and their socio-economic-emotional situations were concerned. Their stated reasons for discontinuing treatment or our inferred reasons for their continuing treatment were examined. Then an evaluation was made of how these socioeconomic-emotional and other factors mentioned seemed to influence their ability to follow treatment and how the patients themselves looked on their treatment and their reasons for continuing or discontinuing.

\section{Duration of known hypertension}

\section{RESULTS}

It seems reasonable to postulate that the longer the duration of known hyper- 
tension the greater the awareness of the potential hazards of inadequate treatment. Our findings support such an hypothesis.

Thirty-one per cent of patients in the emergency group had known of hypertension less than $5 \mathrm{yr}$ contrasted with only 4 per cent of the controls (Table 3 ).

A further analysis revealed that in the emergency group only 43 per cent had known of their hypertension for $10 \mathrm{yr}$ or more; whereas, 63 per cent of the controls had known of hypertension for $10 \mathrm{yr}$ or more.

The duration of known hypertension is in a sense a function of the dropout curve (Fig. 1). The patients who have a short acquaintance with hypertension are much more likely to drop out in the first year of treatment; whereas, those with a longer duration of the disease are more likely to be in the remaining group.

Age

The emergency group was younger than the controls. Forty-five per cent were under age 50 as compared with only 17 per cent of controls (Table 4).

Race

Negroes predominated in the emergency group. Twenty-six of 42 were Negro giving a total of 62 per cent non-white (Table 5). By contrast in the control group there were 5 Negroes and one Chinese or 25 per cent non-white.

\section{Education}

Quite remarkable differences in educational attainments of the two groups were

TABle 3. DuRATION OF DISEASE

\begin{tabular}{lrrrr}
\hline & $0-4$ yr & $5+y r$ & Total & $\begin{array}{c}\text { Percentage } \\
<5 \text { yr }\end{array}$ \\
\hline Emergency & 13 & 29 & 42 & 31 \\
Controls & 1 & 23 & 24 & 4 \\
Total & 14 & 52 & 66 & \\
& & $\chi^{2}=6.6$ & $p<0.01$ & \\
\hline
\end{tabular}

Table 4. Age

\begin{tabular}{lrrrr}
\hline & $<50$ & $50+$ & Total & $\begin{array}{c}\text { Percentage } \\
<50\end{array}$ \\
\hline Emergency & 19 & 23 & 42 & 45 \\
Controls & 4 & 20 & 24 & 17 \\
Total & 23 & 43 & 66 & \\
& & $x^{2}=5.5$ & $p<0.02$ & \\
\hline
\end{tabular}

TABle 5. Race

\begin{tabular}{lcrcc}
\hline & White & Non-white & Total & $\begin{array}{c}\text { Percentage } \\
\text { non-white }\end{array}$ \\
\hline Emergency & 16 & 26 & 42 & 62 \\
Controls & 18 & 6 & 24 & 25 \\
Total & 34 & 32 & 66 & \\
& & $x^{2}=8.3$ & $p<0.01$ \\
\hline
\end{tabular}


apparent. In the emergency group, 72 per cent had less than a high school education. By contrast, only 42 per cent of the controls had not finished high school (Table 6). An additional difference not shown in the table was that 30 per cent of the emergency group had less than an eighth grade education. In both groups, the spouses seemed to have slightly more education than the patients: 35 per cent of the spouses of the emergency group have had high school education, and 71 per cent of the spouses of controls had high school education. But there too, the highly significant educational differences between the emergency and control groups are evident.

\section{Occupation}

Sixty-eight per cent of the emergency group were blue collar workers as contrasted to 31 per cent of controls (Table 7). Only 2 per cent of the emergency group patients held or had held before retirement professional or executive positions as compared with 21 per cent of control group patients.

\section{Income}

Table 8 shows that the majority of the patients in the emergency group were in the low to middle income brackets with most getting $\$ 4000-7999$ income. Ninety

Table 6. Education

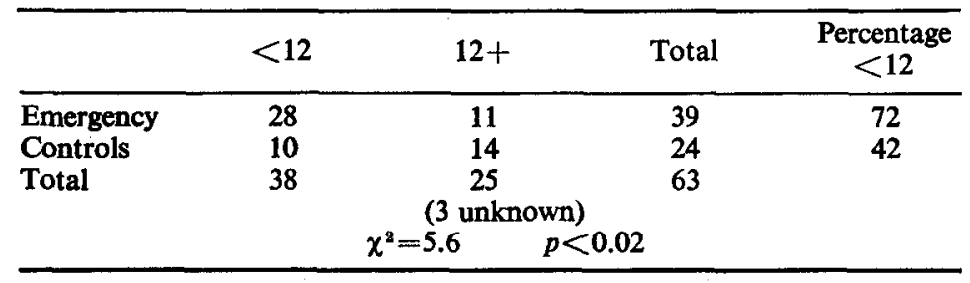

TABle 7. Occupation

\begin{tabular}{|c|c|c|c|c|}
\hline & Blue collar & White collar & Total & $\begin{array}{l}\text { Percentage } \\
\text { blue collar }\end{array}$ \\
\hline $\begin{array}{l}\text { Emergency } \\
\text { Controls } \\
\text { Total }\end{array}$ & $\begin{array}{r}17 \\
5 \\
22\end{array}$ & $\begin{array}{c}8 \\
11 \\
19 \\
\text { (25 housewive } \\
=5.3\end{array}$ & $\begin{array}{l}25 \\
16 \\
41\end{array}$ & $\begin{array}{l}68 \\
31\end{array}$ \\
\hline
\end{tabular}

TABLE 8. INCOME

\begin{tabular}{|c|c|c|c|c|c|}
\hline & $<\$ 4000$ & $\begin{array}{c}4000- \\
7999\end{array}$ & $8000+$ & Total & $\begin{array}{l}\text { Percentage } \\
<8000\end{array}$ \\
\hline $\begin{array}{l}\text { Emergency } \\
\text { Controls } \\
\text { Total }\end{array}$ & $\begin{array}{l}10 \\
9 \\
19 \\
x^{2}=\end{array}$ & $\begin{array}{c}25 \\
5 \\
30 \\
(5 \text { unkno } \\
10.8\end{array}$ & $\begin{array}{r}4 \\
8 \\
12 \\
1) \\
<0.01\end{array}$ & $\begin{array}{l}39 \\
22 \\
61\end{array}$ & $\begin{array}{l}90 \\
64\end{array}$ \\
\hline
\end{tabular}


per cent earned less than $\$ 8000$. By contrast, only 64 per cent of the controls had an income of less than $\$ 8000$ a year. Other figures not shown in the table revealed that 69 per cent of the emergency group had an income of less than $\$ 6000$ as compared to 46 per cent of the control group. The source of income was comparable for both groups and consisted largely of employment, about one-third of each group was getting Social Security, and two of the controls had pensions.

\section{Home ownership}

The financial status as indicated by renting, buying, or owning a home varied between the two groups in that only 31 per cent of the emergency group owned their home; whereas 54 per cent of the control group did. This may be due in part to the fact that the control group were somewhat older. Thirty-three per cent of the emergency group were buying their home and 13 per cent of the control group.

\section{Work status}

Excluding the housewives in both groups, the majority of the patients worked full time. Thirty-eight per cent of the emergency group and 33 per cent of the control group were retired (either on age or for disability). Only 1 patient in the emergency group was unemployed.

\section{Birthplace and adult environment}

Fifty-seven per cent of the emergency group were born in the southeastern United States as compared with 33 per cent of the controls. Similar differences were noted in the birthplaces of the spouses. Most patients in both groups are presently living in the metropolitan Detroit area. There was a slightly greater record of rural, southern, childhood environment prior to moving north to the city in the emergency group than in the controls. These differences in birthplace and adult environment may reflect racial differences in northern urban population trends rather than differences unique to our study.

\section{Family history of hypertension}

Only 36 per cent of the emergency group had hypertension present in parents as compared with 58 per cent of the controls. Forty per cent of the emergency group had no knowledge of hypertension in their family; whereas only 29 per cent of the controls were not acquainted with a family history of hypertension.

\section{Stated reasons for discontinuing treatment}

Subjective and superficial reasons cited by patients for stopping treatment were obtained from the emergency group (Table 9). These reasons were not always in

TABLE 9. STATED REASONS FOR DISCONTINUING TREATMENT

\begin{tabular}{lr}
\hline Emergency group & 42 patients \\
\hline Felt well & 39 per cent \\
Poor instruction & 36 per cent \\
Financial need & 33 per cent \\
Advice of M.D. & 24 per cent \\
Lack of family support & 14 per cent \\
Dissatisfied & 10 per cent \\
Side effects of drugs & 7 per cent \\
Discouraged & 7 per cent \\
\hline
\end{tabular}


accord with the socio-economic data we obtained but offer clues to the information we originally sought as to why patients drop out of treatment. Several reasons were listed by many of those queried. It was admittedly difficult to obtain straight-forward and factual reasons because of complexity of motivation.

\section{Inferred reasons for continuing treatment}

There are listed in Table 10 estimates of conditions in the control group which are helpful in treatment and which would favor a patients' remaining in treatment. These reasons had to be inferred from data obtained since they could not be drawn from direct interviews. Several reasons were given for each person in most instances.

\begin{tabular}{ll}
\hline TABLE 10. INFERRED REASONS FOR CONTINUING TREATMENT \\
\hline Control group & 24 patients \\
\hline Good knowledge of disease & 71 per cent \\
Harmful effects of inadequate treatment & 50 per cent \\
Harmful effects of hypertension in family & 50 per cent \\
Emotional satisfaction & 41 per cent \\
Physical comfort & 38 per cent \\
Family support & 38 per cent \\
\hline
\end{tabular}

\section{DISCUSSION}

The dropout rate is high among new patients attending a clinic for evaluation and management of hypertension. Some of the consequences are quite serious as indicated by the hypertensive emergencies that are reported here.

Because of the complexity of motivation for behavior related to health and illness [6] our approach to the subject can only be regarded as a pilot look at the nature of the problem. The 'stated' reasons for discontinuing treatment and "inferred" reasons for continuing treatment are certainly of some validity but it takes much more than asking, 'why did you quit treatment'? or 'what were your reasons for continuing treatment as prescribed'?

In considering social and emotional factors influencing a patient's ability to follow an antihypertensive program, three main factors stand out; socio-economic factors, learned responses and education of the patient about the disease and its treatment.

\section{Socio-economic factors}

When the emergency group is contrasted with the control group having hypertensive disease of the same severity, distinct differences are notable. The most striking statistically significant differences characterizing the emergency group are socioeconomic (Table 11). They are younger, more likely to be Negro, to have less education, to be blue collar workers and to have less income.

In the emergency group more than two-thirds had less than a high school education

TABLE 11. CharaCteristics OF EMERGeNCY Group

Younger

Negro

Less education

Blue collar workers

Less income 
and more than two-thirds had an income of less than $\$ 6000$ per year. Education and income are inseparably related since educational background is so important in getting a good job which yields a better income. Certainly, also, the education of an individual influences his ability to postpone immediate rewards for more distant objectives and the presence or absence of such an ability would have significant consequences in long term antihypertensive treatment.

As far as income is concerned many of our patients who stopped treatment and subsequently developed an emergency barely had enough income to support the high cost of intensive long term treatment for severe hypertensive disease. Financial needs were cited as the main reason for quitting treatment by 33 per cent of the emergency group. A realistic appraisal reveals that a low income and the cost of medical care was probably a major factor in determining cessation of treatment in at least one-third of the group. However, more sophisticated studies are needed. Financial needs may be cited as a socially acceptable reason and be offered as an excuse for some more fundamental reason.

The fact that blue collar workers were predominant in the emergency group may reflect their lower educational achievement. Working from one brief pay period to the next could favor shorter term planning and is perhaps less conducive to acceptance of long range preventive medical care than more stable income of salaried white collared workers.

The racial differences noted are highly significant and yet a study of data on the interaction of race and education reveals that education seems to account for almost all the Negro-White differences. The expressed reasons for dropping out suggest but do not prove that patients with a high school education expect to understand their treatment program and are dissatisfied when they do not whereas those with less than a high school education are more likely to be satisfied with less understanding. The Negroes with only one exception avoided the response of "dissatisfied or discouraged with the treatment" while Whites more commonly gave this type of response. This may reflect an unwillingness of Negroes to communicate dissatisfaction. Negroes offered financial reasons more than Whites, however this seemed to be in accord with their lower income and reflected real economic hardship rather than simply a socially acceptable reason for quitting treatment.

Using the criteria of education and income we can conclude that patients in the emergency group were in a lower social class than were those who remained in treatment. It has been observed that there is a class difference with respect to remaining in psychotherapy. Frank [7] found the dropout rate for lower class patients is about double that for middle class ones. Patients in our study who had better jobs and more income were likely to be in the control group and to be better off in many ways. Patients in the lower socio-economic levels have a greater need for property, for educational status and for money to meet the costs of daily living. They are therefore faced with daily economic needs which may conflict with their health needs. This leads to a different sct of valucs than arc held by the patients with higher socio-economic status. Patients in a higher social class are more likely to have more property, to own their homes (especially the older individuals), to value their health more highly, show a greater tendency to make long range plans and more readily accept the idea of long range preventive medical care.

Rubinstein and Lorr [8] studied terminators and remainers in out-patient psycho- 
therapy and noted that terminators were more aggressive, apt to act our their feelings, and hostile to authority. We have wondered whether personality factors were significant in patients discontinuing antihypertensive treatment. We did not study intensively personality factors in the 2 groups of patients we compared, but we have the impression from our study that education and economic position were more important than personality attributes in determining regular attendance in the clinic. In short, education, income, occupation, race and social class were the socioeconomic factors of most importance in influencing a patient's ability to follow an antihypertensive program.

\section{Learned responses}

Many patients who remained in treatment had learned through bitter experience that regular attendance in long term antihypertensive treatment was advisable. This type of learning has much in common with a conditioned response. Conditioned reflexes are dependent not alone on the activity of the nervous centers in the cord or other sub-cerebral parts of the nervous system but on cerebral activity aroused and organized by special experience or training and in psychologic terms, involving the functions of association and memory [9].

A hypertensive emergency itself would act as a stimulus to lead the sufferer to seek medical care. Certainly a repetition of such a frightening experience would encourage the patient to remain in treatment. It should be noted that some of those who were originally in our emergency group have since done so well in long continued treatment that they will probably qualify as control subjects after $5 \mathrm{yr}$ have elapsed.

Fifty per cent of those remaining in treatment had personal experience of the harmful effects of no treatment or inadequate treatment. Fifty per cent of those remaining in treatment reported harmful effects of untreated hypertension in members of the family. A combination of such experience, both personal and familial, would reinforce the resolve to remain in treatment. There was strong family support encouraging the patient to stay in therapy in 38 per cent. By contrast lack of family support was a factor influencing the stopping of treatment in 14 per cent of the emergency group. Sometimes this amounted to strong encouragement by the spouse to stop going to the doctor. There was a stronger family history of hypertension in controls than in the emergency group. This too if combined with unfortunate consequences of untreated hypertensive disease in family members would tend to lead the controls to remain in treatment.

Thirty-eight per cent of those continuing treatment said they had more physical comfort while under antihypertensive drug therapy. This reason is difficult to distinguish from harmful effects of inadequate treatment. Considered together they imply that a fairly large number of patients who remained in treatment did so because of disturbing symptoms that recurred if treatment was stopped. Such symptoms, milder, less dramatic and life threatening than a hypertensive emergency are perhaps 'fortunate reminders' of a need for continuing treatment for some patients.

The fact that the emergency group was younger and had a shorter duration of known hypertension than the control group bears further consideration. It is probable that patients would be selected as controls or would fall in that group due to the 
characteristic of the dropout curve if they had a longer duration of the disease (Fig. 1).

However, it is probable that learned responses are operative in the continued treatment of the older patients with disease of longer duration. The younger patient with a shorter history of hypertension would be less likely to have learned through experience of the importance of regular medical care and of the effectiveness of modern, long term antihypertensive treatment. The control group being older and having a longer acquaintance with their disease are in a better position to take appropriate action to prevent an emergency by following a careful medical regimen. A repetition of harmful experiences in a person with long duration of disease would act as a learned pattern of behavior to favor his remaining in treatment.

It is notable that side effects of drugs accounted for a very small number ( 7 per cent) of the reasons given for discontinuance; and that 29 per cent remained in treatment despite undesirable side effects of drugs. So, that, in the control group all of the many factors encouraging patients to remain in treatment outweighed serious financial and other obstacles faced by many patients in need of long term antihypertensive treatment-a treatment which is often expensive, time consuming and not without certain pharmacologic and social drawbacks. In the control group, also, a long experience with treatment and no trouble from disease or medication during that experience would tend to favor continuation of therapy for "why quit a winning combination'.

\section{Education of the patient about the disease and its treatment}

Unless the physician has gained some experience in the successful treatment of patients with severe hypertensive disease he will hardly be in a position to educate the patient. What the physician should teach the patient is beyond the scope of this paper but in brief it is the importance of maintenance of near normal blood pressure usually principally by diet and drugs, and the ways that this is to be accomplished. This educational process involves introduction of the preventive medicine concept. In many instances not only the patient but the spouse as well should be brought into the discussions. Of the patients who remained in treatment (control group) 71 per cent appeared to have remained primarily because of a good understanding of their disease and good instruction by the physician. By contrast in the emergency group 39 per cent stopped treatment because they felt well. Having a sense of well being without treatment they saw no need to continue the drugs. Many patients did not realize that 'feeling well' did not necessarily mean 'being well'.

This feeling that everything would go along all right without treatment was often combined with the complaint of not having enough money to return for regular office visits. Thirty-six per cent stated that they had not been told that treatment should be continuous and should never be stopped except under medical supervision. We listed these replies as 'poor instruction' by the physician although they may have reffected a lack of understanding by the patient or inadequate emphasis in the physician's instruction of the patient. The large number of patients who dropped out of treatment because they did not know they should continue under medical supervision highlights the need for the physician to educate the patient about his disease.

Another 24 per cent quit treatment on advice from a physician. Certainly there 
will be occasions when all antihypertensive drugs should be stopped, but the temporary cessation of drug treatment should not be confused with a long term discontinuance of therapy. It is probable that in some of these cases there was an error in medical judgment or a need for physician education in the proper administration of an antihypertensive program.

\section{Keeping patients in treatment}

If patients are to benefit from the improved morbidity and mortality from hypertensive diseases which modern antihypertensive therapy offers, the dropout problem must be realistically approached. If the patient does not keep appointments and fails to take drugs as prescribed, the net effect is the same as taking drugs which have no pharmacological efficacy. In the light of advances in the past $10 \mathrm{yr}$ we can now say with confidence that hypertension usually can be controlled with continuous, adequate, therapeutic management.

Probably the most important influence in keeping the patient in treatment is the physician. A good physician-patient relationship is of paramount importance to the success of any long term therapeutic process. Forty-one per cent of the control group apparently had an emotional satisfaction from regular attendance. The attitude of nurses, receptionists, technical assistants and other paramedical personnel as well as the physician all would contribute to a sense of emotional satisfaction a patient may experience. Some patients behave in the clinic as if it were a cracker-barrel country store-a center for an enjoyable social activity. Other patients remain in part because they have adopted a dependent, sick role behavior. This is not always in accord with the severity of disease or need for antihypertensive treatment. However the majority seem to be in regular attendance for relief of symptoms or because of a healthy urge to stay well.

Some patients in the emergency group were dissatisfied (10 per cent) with the type of medical care received. Probably the most frequently expressed dissatisfaction was in reference to a rotational system in use in the clinic which necessitated some patients seeing a different doctor at every visit. We did not study the dropouts to find out if a much greater dropout rate occurred when the therapist was a rotating physician. However, knowing the important role of the physician-patient relationship in all medical care, we would expect the dropout rate to be higher in the patients seeing rotating physicians. We would also expect that a somewhat greater number of patients in the lower social classes would be on the lists of the rotating physicians than on the lists of permanent staff physicians. Without benefit of additional studies we have concluded that a rotational system such as is used in many clinics is an unsatisfactory method for management of patients with hypertensive diseases. Frequently this in itself may lead to abandonment of therapy sometimes with fatal consequences. However, due to the medical manpower shortage in some situations it is the only practical means of meeting the shortage of well-qualified physicians engaged in the continuous care of patients who are being managed for chronic illness in clinics.

Some patients who were discouraged quit treatment because of an 'I don't care' attitude or deliberate decision to quit treatment and take the consequences whatever they may be. In cases like this, which may represent a denial of illness, persuasion by the physician may be most effective. Some patients sense rejection by the physician 
and become discouraged or dissatisfied. The physician may overcome such feelings by his attitude or he should refer the patient to another doctor.

Education of the patient and spouse about the patient's disease and its treatment is a most important measure in keeping the patient in treatment. From a study of the dropout curve (Fig. 1) one can see that special efforts are needed at the initiation of treatment. Special efforts are needed for the poorly educated and for those in financial distress. It also seems apparent that continued encouragement and reeducation of patients is indicated at the very time when they are feeling well and have been going along fine for some time.

For those who are in need it is important to use the social resources of the community. Indeed, for this reason and because of the importance of socio-economic factors influencing the course of the disease it would be desirable to have the social worker see the patient early in the course of his illness. In medical facilities where medical social workers are available the early enlistment of their assistance should benefit the patient and physician and reduce the likelihood of a dropout problem.

Some physicians and many dentists have a systematic method for calling in patients for re-examination and follow up visits. Adoption of such a system for follow up of patients requiring continuous care might do much to reduce the dropout rate. A registry of patients could be maintained. In this way patients who might might otherwise terminate treatment with dire consequences could be called in for a return appointment at a time when preventive measures were still possible. It should be recalled that frequently one or more years had elapsed between the time the patient discontinued therapy and the development of the hypertensive emergency. A registry such as proposed here could be instituted by clinics and practitioners alike. However, more research is needed to find out whether the dropout problem is as great from the private practitioners as it is from the clinics.

\section{CONCLUSION}

The dropout problem in antihypertensive treatment is an important aspect of the management of hypertensive diseases. This problem has emerged as a consequence of the effectiveness of modern antihypertensive therapy. We have found that the dropout rate is high and merits further study.

Patients who discontinue antihypertensive treatment may develop hypertensive emergencics which might well have been prevented by regular attendance in medical care, therefore there is a need for life long medical supervision in patients with an established diastolic hypertension. An improvement in mortality may result from emphasis on the need for continuous, long term therapy.

To study reasons why patients drop out of treatment 66 patients were evaluated medically and in terms of social-emotional factors. Data was gathered from medical records and personal interviews. An emergency group of 42 patients had had a hypertensive emergency after discontinuing theatment. The control group of 24 paticnts had had prolonged consistent treatment with good control of their disease. The pretreatment severity of hypertensive disease was comparable in the two groups.

The emergency group showed statistically significant differences from the control group. They are younger, have had their disease for a shorter time, have less education, less income and are more likely to be Negro blue collar workers.

Three main factors stand out as influencing a patient's ability to follow an anti- 
hypertensive program, socio-economic factors, learned responses and education of the patient about his disease. The socio-economic status of the patient and psychological and emotional factors may have a profound influence on the course of hypertensive diseases and may be crucial factors in determining whether a patient will live well with his disease, will have recurrent disability and morbidity from the disease and in some cases whether he will die from his disease.

A preliminary approach to the problem of keeping patients with hypertension in treatment is presented. It involves education of the patient and spouse, special efforts at the initiation of treatment for the poorly educated and needy and for those who feel well. It also involves use of social resources of the community for those in need and a registry of patients. Finally the education of the patient by the physician is of the greatest importance to the success of the therapeutic regimen. Appropriate long term management of hypertensive diseases can result in improved morbidity and mortality from these diseases and the rewards for the patient and physician alike, would well justify the effort.

Acknowledgements-The authors wish to thank Mrs. Edith McKnight and Mrs. Chi Chen of the Department of Social Work for their part in interviewing patients for this study. Also we are indebted to Drs. Robert Kandel and Peter Johnston of the Emergency Division of the Henry Ford Hospital for their cooperation and assistance in this work.

\section{REFERENCES}

1. Harvey WP, Kirklin JW, Nadas AS, et al: Hypertension, Year Book of Cardiovascular and Renal Diseases, 1962-1963. Chicago, Year Book Publishers, 1963

2. Smirk FH: High Arterial Pressure. Oxford, Blackwell Scientific Publications, 1957

3. Keith NM, Wagener JP, Barker NW: Some different types of essential hypertension: their course and prognosis. Am J Med Sci 197: 332-343, 1939

4. Sokolow M, Lyon TP: The ventricular complex in left ventricular hypertrophy as obtained by unipolar precordial and limb leads. Am Heart J 37: 161-186, 1949

5. Caldwell JR, Hollinger FW: The importance of basal blood pressure. Henry Ford Hosp Med Bull 3: 175-185, 1955

6. Kasl SV, Cobb S: Health behavior, illness behavior and sick role behavior. Archs Environ Health 12: 531-541, 1966

7. Frank JD, Gliedman LH, Imber SD, et al: Why patients leave psychotherapy. Archs Neurol Psychiat 77: 283-299, 1957

8. Ibid

9. Rosanoff AJ : Manual of Psychiatry and Mental Hygiene, New York, Wiley, 1938 